\title{
Precision rock excavation: beyond controlled blasting and line drilling
}

\author{
Marilena Cardu ${ }^{1,2 *}$, Simone Saltarin ${ }^{1,2}$, Carmine Todaro ${ }^{2}$ and Chiara Deangeli ${ }^{1}$
}

1 Department of Environment, Land and Infrastructure Engineering-DIATI, Politecnico di Torino, Italy

2 National Research Council, Geosciences and Georesources Institute-IGG, Politecnico di Torino, Italy

* Correspondence: marilena.cardu@polito.it

\begin{abstract}
The strictness of the result of an excavation, whether mechanical or by means of explosives, is naturally conditioned by the objective, and therefore by the type of technique applied to achieve it. To attain the best results in terms of rock breakage and respect of the final profile, it's important to evaluate the excavation specific energy and its optimization. This research focuses on evaluating the effects of different techniques on the quality of final walls in open-pit and underground operations. Different geometries and configurations can be applied to both quarrying and tunnelling blasts. The research is aimed to push contour blasts to their limits, and the main aspects are discussed in order to improve the blast parameters in the daily practice.
\end{abstract}

Keywords: presplitting, smooth blasting, line drilling, mechanical cutting, controlled blasting.

\section{Introduction}

Michelangelo was supposed to say that sculpting is a trivial operation, as it consists in just removing the excess from a block of stone.

Paradoxically, the sculptor's problem is sometimes simpler than the one which is faced every day by those who carry out rock excavations requiring a very accurate outline: the added value of a statue (in particular, of a Michelangelo's statue) compared to the rough block is so much enormous, which does not matter how the "excess" is removed: the sculptor could remain competitive while consuming the "excess" with a precision cutter, yet he too follows a principle of economic optimization: the first hammer blows are able to break large volumes to roughen the statue, then the strokes become more delicate, to bring out the details, and finally the manufacture is carried out by applying techniques of higher unit cost, to remove progressively smaller volumes. The Crazy Horse project is the largest sculpture in the world made by Drill and Blast, hereinafter D\&B [1], and is a spectacular example of the partnership between the art and engineering of explosives (Figure $1(\mathbf{a})$ ). Every construction project has site specific problems that need to be dealt with: these problems may be posed by the geology, location, time constraints, etc. Once they have been solved, their solution often can be transferred to other similar construction sites. The Crazy Horse Memorial is no exception: the problem was unique and site specific, but the solution can be used on other construction projects. To design the blast, drill patterns were conceived according to the geology of the mountain, and both downholes and horizontal holes were performed to leave a clean wall with the minimum back-break; comprehensive blasting records were kept, including vibrations; blast dimensions; amount of rock remove; amount and type of explosives used; number, diameter, spacing and depth of boreholes; number of delays; type of drilling; personnel needed; time it took to drill; weather and costs.

People who work in the field of rock excavation, to realize the huge sculptures (tunnels, trenches, shafts, quarries, etc.) usually behave in a similar way. The bulk of the rock removal work, up to a given distance from the design contour, is performed at a low unit cost with ordinary production blasts, and then moves on to a much more expensive and 
controlled excavation or to another technique, such as mechanical cutting, to refine the profile.

The goal of blasts (apart from cases where only the detachment effect is desired) is to transform a predetermined volume of rock on site distribution into debris of a given grain size.

The minimum that can be expected is that the blast reduces a certain volume of rock to a transportable size, with a tolerable percentage of oversize. The maximum ("perfection") is that it detaches and reduces to fragments of specified particle size distribution all and only the volume that the blasting plan assigns to it, leaving a cavity with regular, stable walls and, obviously, corresponding to the design geometry.

Coming back to the case of the sculpture, if the surface that, in the block, ideally separates the statue from the "excess" were not an ideal surface (the outline of the work, which is in the artist's mind), but a real, physical, discontinuity, the artist could simply break the crust with a few, inattentive blows of the hammer to obtain the desired result.

Since there is no such a surface, it be created in advance: this is generally impossible for the sculptor, due to the complicated outline of the statue (although it is sometimes possible to apply this concept to the case of roughing, as can be seen in Figure 1 (b)), but it is often applicable to ordinary excavations.

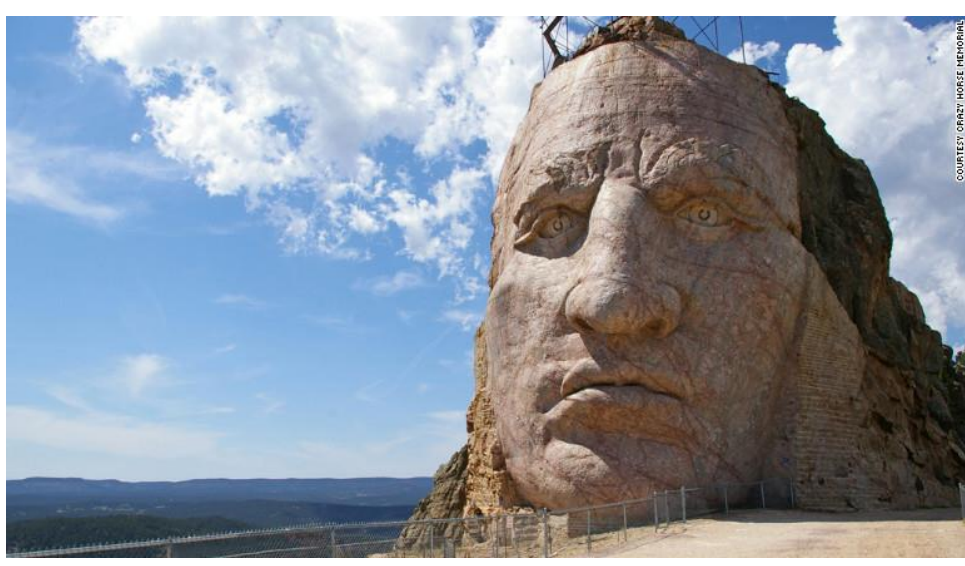

(a)

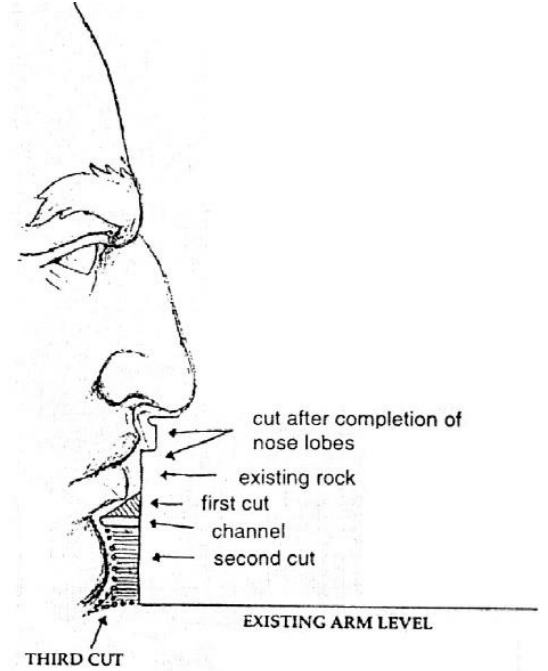

(b)

Figure 1. Left: the Crazy Horse Memorial, a Native American monument, carved with explosives in the granite of the Black Hills, South Dakota [1] (a). Right: dimensions of the face of the "Crazy Horse" and detail of the execution phases of the profile's roughing by explosive. Whole face, height $26,7 \mathrm{~m}$, width 17,7 m; forehead, height 9,7 m; eyebrows, height 6 $\mathrm{m}$, width 2,3 m; eye opening, height 2,4 m, width $1 \mathrm{~m}$; nose, height 8,2 m, width 5,2 m; lips, max height 1,8 m, max width $5,8 \mathrm{~m}[2](\mathbf{b})$.

In this paper, the main techniques adopted to control the rock removal process (that becomes a real shaping of rock, in the case of sculptures) are considered. Presplitting, smooth blasting and mechanical cutting are firstly presented from a theoretical point of view. Secondly, concrete applications of these techniques are reported. The last part proposes a comparison between the techniques most commonly adopted to date. The work can represent a useful tool for both civil and mining engineers, since it reports in a compact way the main information to correctly apply the described technologies. Furthermore, the comparison between them can represent a tool able to guide the stakeholders to correctly select the best solution for a given application. 


\section{Excavation technique and the compliance with excavation contour}

Examples of production blasts applied to two different construction sites (as far as the purpose of the job is concerned) are given in Figure 2, where an open pit quarry for the exploitation of limestone and a round for tunnel driving are represented. The level of precision required in the two cases is obviously different: in the first, the objective is the productivity to be reached $\left(\mathrm{m}^{3} / \mathrm{d}\right)$ and generally no attention is paid for respecting a given geometry, except in the phases close to the final profile, whereas, in the second, the objective is to obtain a regular cavity, so that each blast must be designed in order to ensure compliance with the final contour.

In many cases, the goal is to allow the isolation of a certain volume of rock, without causing damage to the rock mass that will remain in place.

The final profile can also be made with common production blasts but, in order to reduce the extent of damage in the rock mass, techniques can be used, some through Drill \& Blast, others through mechanical excavation, which allow to optimize the result.

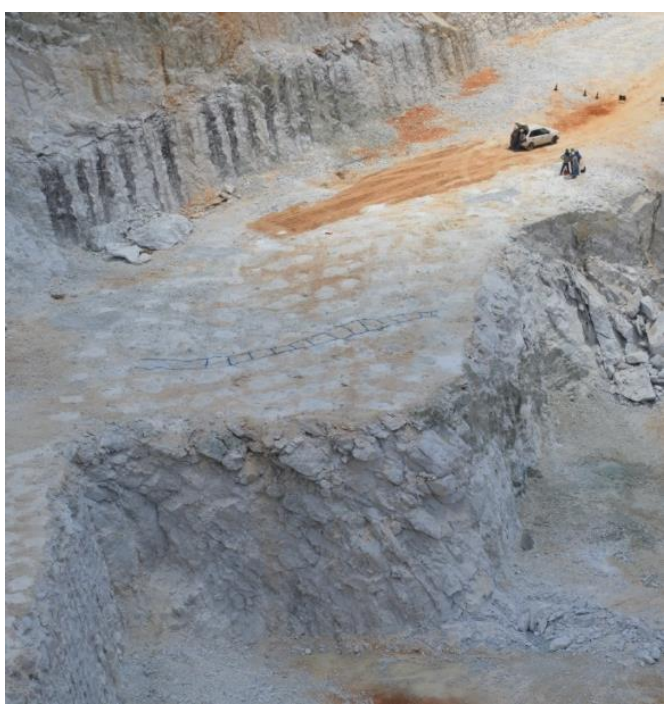

(a)

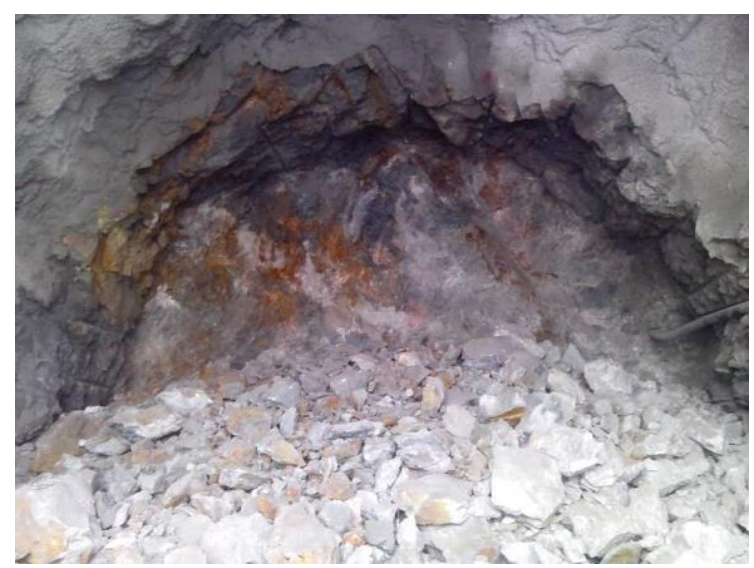

(b)

Figure 2. Examples of ordinary blasts: above, production blast in a limestone quarry, Brazil [3] (a); right, tunnel face after a blast: the poor quality of the contour obtained is noticeable [4] (b).

These techniques can be listed as follows:

- Presplitting: it consists in making a pre-cut in the rock mass, performed by means of explosives, to be carried out before the production blast. Table 1 shows the values commonly adopted for this operation.

Table 1. Range of parameters commonly adopted in the presplitting.

\begin{tabular}{|c|c|c|c|c|c|}
\hline \multicolumn{2}{|c|}{$\begin{array}{l}\text { Hole's diameter } \emptyset_{\mathrm{f}} \\
(\mathrm{mm})\end{array}$} & \multicolumn{2}{|c|}{$\begin{array}{l}\text { Charge density } q_{c} \\
(k g / m)\end{array}$} & \multicolumn{2}{|c|}{$\begin{array}{l}\text { Spacing } E_{c} \\
\text { (m) }\end{array}$} \\
\hline $\min \emptyset_{f}$ & $\max \emptyset_{f}$ & $\min \mathbf{q}_{\mathrm{c}}$ & $\max \mathbf{q}_{\mathrm{c}}$ & $\min E_{c}$ & $\max E_{c}$ \\
\hline 38 & 44 & 0.07 & 0.17 & 0.30 & 0.45 \\
\hline 51 & 64 & 0.17 & 0.29 & 0.45 & 0.60 \\
\hline 76 & 89 & 0.17 & 0.66 & 0.45 & 0.90 \\
\hline 102 & 102 & 0.29 & 1.17 & 0.60 & 1.20 \\
\hline
\end{tabular}

- Smooth blasting: the technique, although having many similarities with presplitting, is based on the fact that the contour holes are blasted after the production holes rather than preliminarily. Also in this case, the technique is effective if the blast holes (with a diameter of 32 or $51 \mathrm{~mm}$ ) are made with extreme precision and if the initiation is, 
as far as possible, simultaneous. Since the smoothing holes must detonate last, they only have to "refine" the work and, therefore, for the purpose of sizing, it has to be considered that these holes must break down a reduced volume of rock, left over after the blasting of the last row of production holes. The calculation parameters therefore differ from presplitting (where the distance from the free surface parallel to the drilling surface was undefined), and it is therefore possible to increase the spacing between blast holes (reducing the specific drilling) thanks to the presence of a free surface next to the holes. Table 2 shows the parameters commonly adopted when performing smooth blasting. An example of the results obtained is given in Figure 3.

Table 2. Common parameters adopted to size the smooth blasting.

\begin{tabular}{|c|c|c|c|c|c|}
\hline & $\begin{array}{c}\text { Hole diameter } \\
(\mathrm{mm}) \\
\boldsymbol{\emptyset}_{\mathrm{f}} \\
\end{array}$ & $\begin{array}{c}\text { Charge diameter } \\
(\mathrm{mm}) \\
\varnothing_{\mathrm{c}} \\
\end{array}$ & $\begin{array}{c}\text { Cherge density } \\
(\mathrm{kg} / \mathrm{m}) \\
\mathrm{q}_{\mathrm{c}} \\
\end{array}$ & $\begin{array}{c}\text { Spacing } \\
\text { (m) } \\
E_{c} \\
\end{array}$ & $\begin{array}{c}\text { Burden } \\
(\mathrm{m}) \\
\mathrm{V}_{\mathrm{c}} \\
\end{array}$ \\
\hline \multirow{2}{*}{ Values measured on-site } & 32 & 17 & 0.22 & $0.40-0.60$ & $0.55-0.75$ \\
\hline & 51 & 25 & 0.50 & $0.65-0.90$ & $0.80-1.20$ \\
\hline \multirow{2}{*}{ Values suggested by [5] } & 32 & - & $0.18-0.38$ & 0.60 & 0.90 \\
\hline & 51 & - & 0.18.0.38 & 0.75 & 1.05 \\
\hline
\end{tabular}

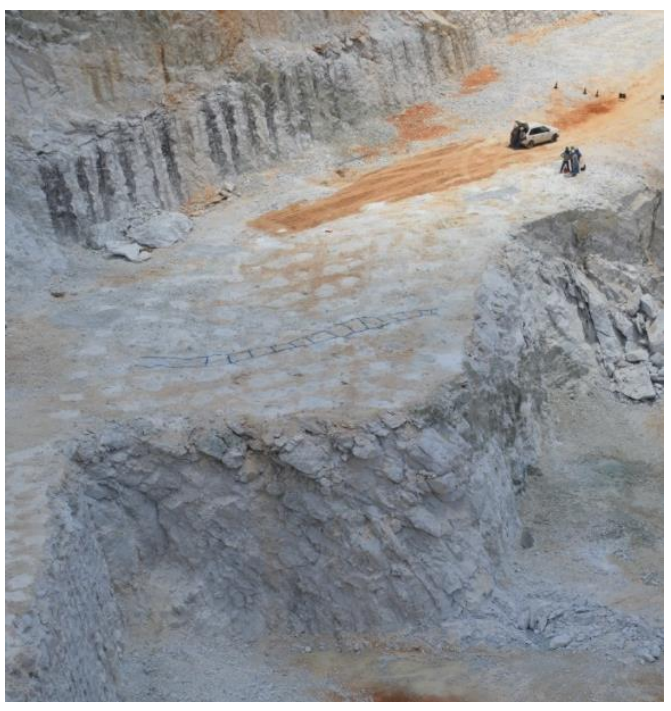

(a)

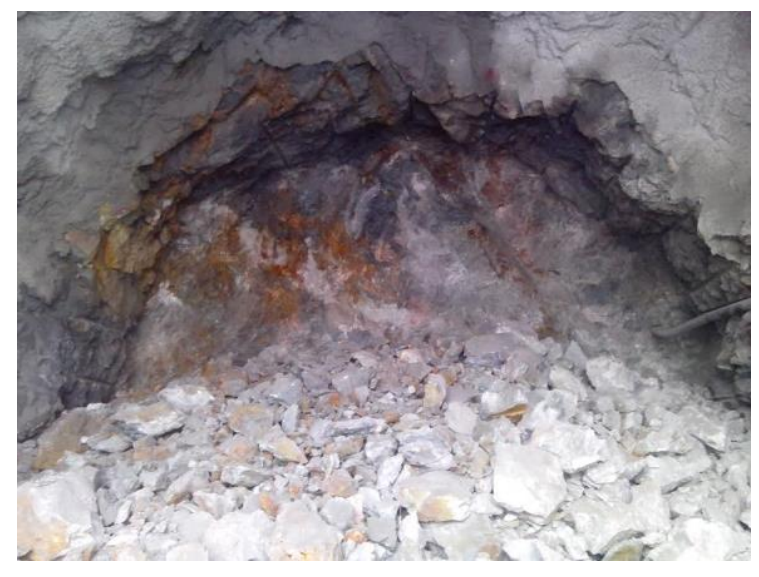

(b)

Figure 3. Examples of smooth blasting. Left: half cast clearly observable after a blast in tunnel driving (a); right: result of a contour blast in open pit mining [4] (b).

The accuracy of the result is mainly influenced by the following factors: geological features; geomechanical characteristics of the medium; presence of water; inclination of the final profile; expected life span of the intervention (example: 1 year; 5 years; unlimited).

However, it should be remembered that the main factor affecting the success of the result, in each of the techniques described below, is the drilling accuracy [6].

- Mechanical cutting:

- Line drilling: it consists in making a single row of side-by-side and interfering holes, thus obtaining a discontinuity between the material to be removed and that intended to remain in place. Figure 4 shows an example of this technique. The artificial discontinuity (called diaphragm) allows to dampen the vibrations generated during the production blast, thus obtaining a final excavation profile with good geomechanical characteristics [7]. 


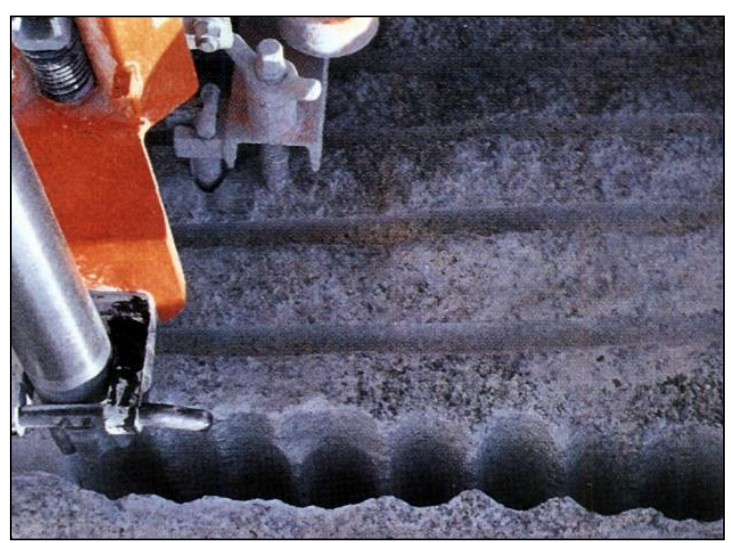

(a)

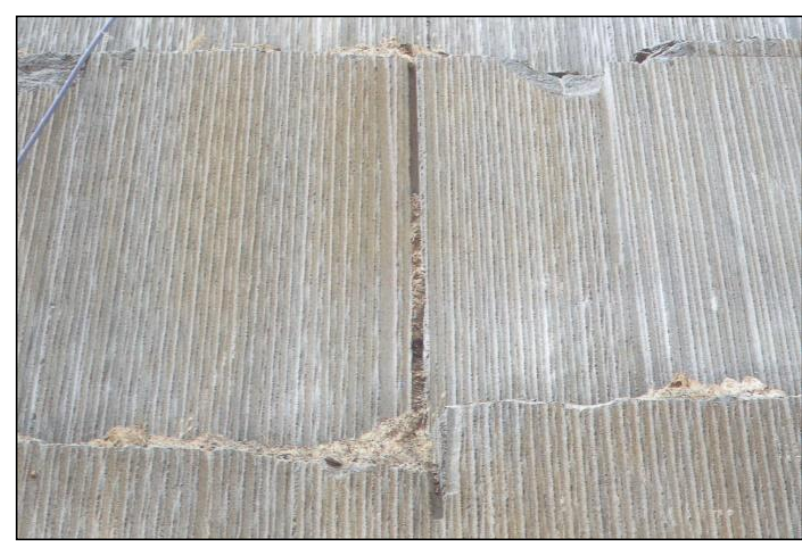

(b)

Figure 4. Left, drilling of contact holes in granite using the line-drilling technique (a). On the right, a granite quarry face cut with line drilling [8] (b).

Drilling diameters between 38 and $76 \mathrm{~mm}$ are normally adopted. Line drilling is mainly applicable in homogeneous rock masses with weak fractures; its application is generally limited, also due to some contraindications, including the difficult prediction of the certainty of effect, except in very homogeneous rocks;

- Diamond wire saw: Cutting with diamond wire is the most widespread technology today in both soft and hard stone quarries, thanks to the considerable progress of the sintered beads, which have made it possible to overcome the problems related to the abrasiveness of the materials to be cut. Its introduction has deeply modified the way of working in stone quarries, allowing very high productivity and improving aspects of health and - with the due precautions - safety at work. The "standard" application of the wire foresees the creation of a closed circuit within which the wire runs at high speed, always cooled by flowing water; the stone is progressively cut by the creation of a deeper and deeper kerf. The circuit for the wire consists in the preliminary drilling of two intersected holes, virtually positioned along the edges of the rock portion to isolate. The wire is inserted into this path and then it is closed as a ring and positioned around the external edge of the motor fly-wheel of the machine. During the cut, the machine moves backwards, usually running on tracks, therefore keeping the wire in continuous tension and in contact to the rock, thus producing a cut through progressive abrasion of the rock mass. The cutter is able to operate according to different anglings, simply tilting the motor fly-wheel. A scheme of a standard application is given in Figure 5, together with a detail of the main components of the machine.

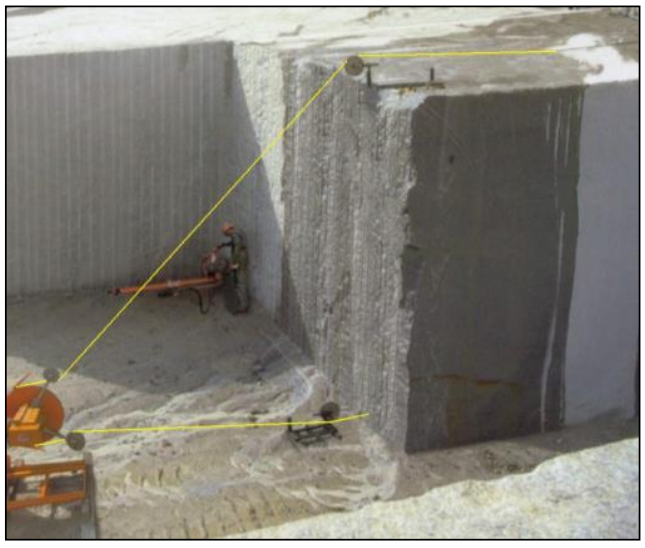

(a)

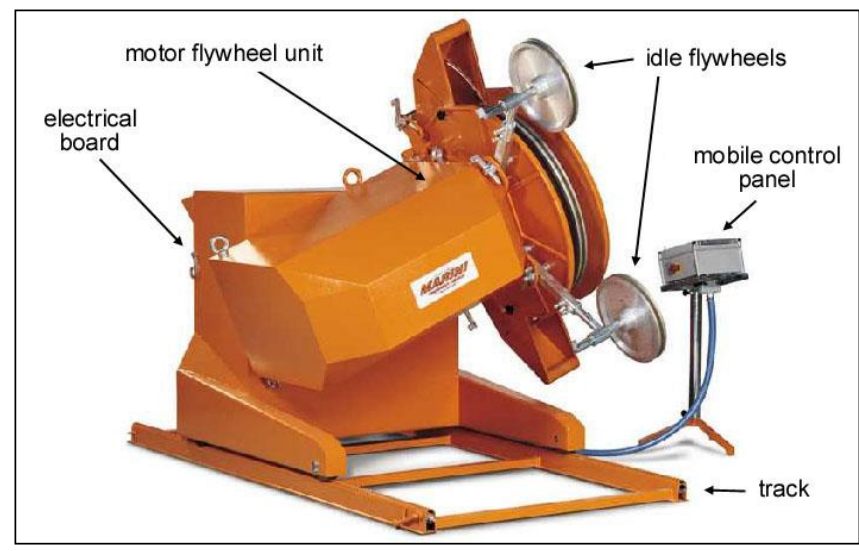

(b) 
Figure 5. Left: cutting by diamond wire through a traditional "descending loop" configuration (a); right: the diamond wire sawing machine, where the main components are shown $(\mathbf{b})$.

- Chain saw: it is produced in two principal versions, that differ for the technical solutions adopted to operate on a bench, or in underground quarries (Figure 6). In the "bench type", the machine is composed by an engine mounted on a frame and connected to a mobile arm, along which runs a toothed chain. The machine can run on rails through a rack. The engine unit, with a power usually ranging from 44 to $60 \mathrm{~kW}$, includes three electro-hydraulic systems, respectively appointed to the movement of the chain, the movement of the arm and the movement of the frame on rails. The tools are made by sharp pieces of widia, or of polycrystalline diamond (Stratapack), which are lodged on special supports fixed along the chain. The chain runs along the perimeter of the arm, continually lubricated by grease. The arm, able to rotate by $360^{\circ}$, consists in a tabular-shaped steel element (about $40-50 \mathrm{~cm}$ wide and $34 \mathrm{~mm}$ thick), whose length does not usually exceed $5 \mathrm{~m}$ (even though arms up to $10 \mathrm{~m}$ in length have been made). The cut has a total thickness of $38-42 \mathrm{~mm}$, a theoretically endless length (in horizontal), but a depth limited by the length of the arm. The parameters needed to optimize the relationship between cutting speed and tools wear are the advancement speed of the machine $(\mathrm{cm} / \mathrm{min})$ and the rotation speed of the chain $(\mathrm{m} / \mathrm{s})$. In the "tunnel type", the arm is mounted on a tubular frame, separated by the engine unit. The arm is usually $3.5 \mathrm{~m}$ long; the frame is $5-6 \mathrm{~m}$ wide and $3.2-4.5 \mathrm{~m}$ high. Thanks to the movement on the frame, both horizontal and vertical cuts can be performed.

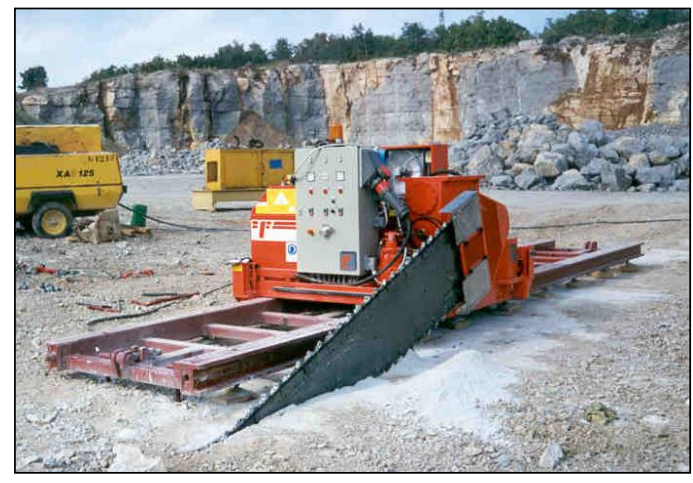

(a)

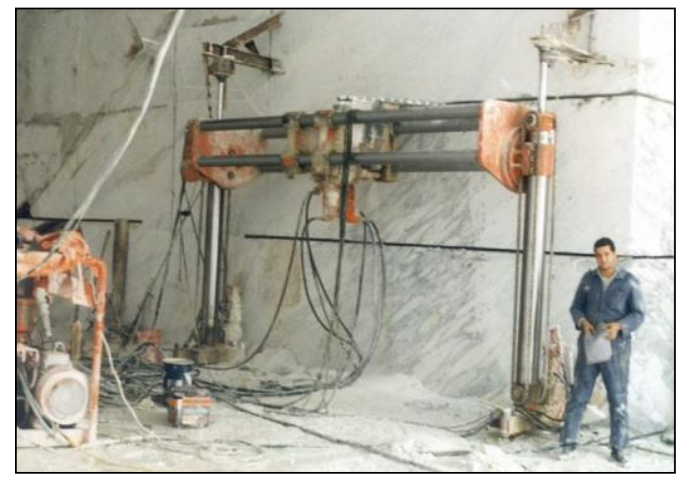

(b)

Figure 6. . Left: a chain cutter operating on a bench to perform a vertical cut (a); right: the version commonly adopted in underground: the versatility of this machine allows the creation of additional free surfaces in bottom-blinded openings of "weak" stone quarries, for which it is very frequently adopted (b).

Anyway, how is it possible to judge if a certain excavation work has been performed correctly in terms of final profile? Of course, the question is challenging, but it is a direct way for introducing the concept of the quality of the work done. The perfection is practically never reached, but it can be used as a goal to judge the quality of the result, which will be much better the closest it gets to the perfect result. Quantitative indicators of the "distance from the perfection of the result" have to be used, and also criteria to distinguish the imperfection that is to be attributed to the medium from that which belongs to defects in the design or execution, and which therefore can be improved by the operator.

The main points to be examined are the respect for the outline of the project and the state of the walls. In D\&B applications, the ideal result would consist in the perfect coincidence of the plane of the contour holes with the residual wall. This rarely occurs. Ordinary blasts usually involve more rock than the design provides and, even when the excavated volume matches the calculated one, it is rarely distributed as the design predicts. 
Apart from any errors in the positioning and direction of the holes, the most frequent discrepancies between the actual and the ideal result are:

- retraction of the edge of the residual bench with respect to the alignment of the mouths of the contour holes;

- protrusions and indentations, with respect to the alignment of the holes, of the bench;

- vertical profiles of the face not straight, as the drawing would like, but with indentations and overhangs.

These inaccuracies, during the excavation, make the correct setting of the next blast difficult or impossible; at the end of the work, the damage will consist in the failure to respect the final outline.

Checking the extent of the inaccuracies naturally implies the detection of a certain number of vertical profiles of the residual face, regularly spaced out and in a statistically significant number to rebuild an average profile.

The results of the surveys are compared with the project to calculate the volume removed in excess (overbreak) compared to what was foreseen by the design geometry.

With an engineering approach, two very useful synthetic indicators of the goodness of the result can be obtained from the survey:

- the average overbreak $\mathrm{OB}(\mathrm{m})$, which is the ratio between the volume removed in excess and the face area;

- the average backbreak, RS (m), which is the average setback of the edge of the bench with respect to the alignment of the contour holes (this indicator is easier to detect than the previous one).

The most frequent cause of excessive backbreak is an excessive charge, but it is certainly not the only one, and on the other hand it is not possible to brutally solve the problem by reducing the charge, because this can harm fragmentation.

Another very useful and easy to detect indicator is the so-called Half Cast Factor (HCF), given by the ratio (percentage) between the total length of "half casts of the holes" observable on the residual wall after the blast and the total length of the contours holes that had drilled and blasted.

\section{Applications}

\subsection{Presplitting}

The first important uses of these techniques were in the field of rock excavation performed by explosives; it has led, over time, to a currently mature and widespread solution (Figure 7). The split surface is a fracture obtained by applying a well-measured and directed tensile impulse to the rock. This is the cheapest way, in terms of time and energy cost, to obtain a discontinuity, which has practically no limits in terms of extension. However, the accuracy of the surface and the certainty and predictability of obtaining the desired effect still need to be improved, especially in anisotropic and inhomogeneous materials. 


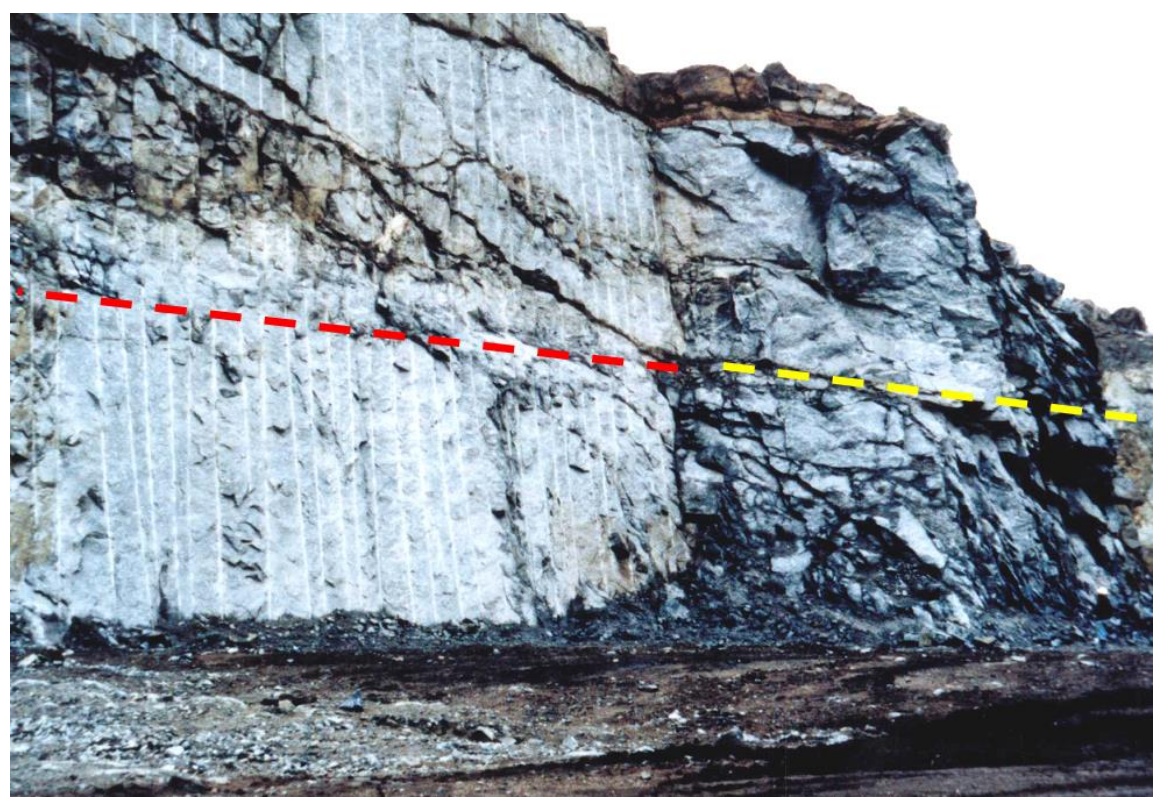

Figure 7. Comparison between the results achieved by pre-splitting blasting (left - red dashed line) and normal blasting (right - yellow dashed line) for a surface excavation [9]. If the parallelism of the holes, the correct spacing and a good decoupling between the diameter of the holes and that of the charge are respected, the result is a profiled wall, where no new fractures are observed in addition to the pre-existing ones

A schematic representation of the presplitting theory is shown in Figure 8, where two charges are triggered simultaneously in adjacent holes: the collision of the shock waves deriving from the detonation stresses the rock bridge between the charge axes, and produces a clear fracture [10]. This fracture subsequently widens thanks to the expansion of gases, depending on three factors: 1) properties and conditions of the rock; 2) spacing between the holes; 3 ) amount and type of explosives. Following the detonation of the charges, a discontinuity is thus obtained which must minimize or eliminate the overbreak due to the subsequent production blast and which gives rise to a regular and flat wall. Two examples of holes charged according to the conditions imposed by the presplitting are given in Figure 9.

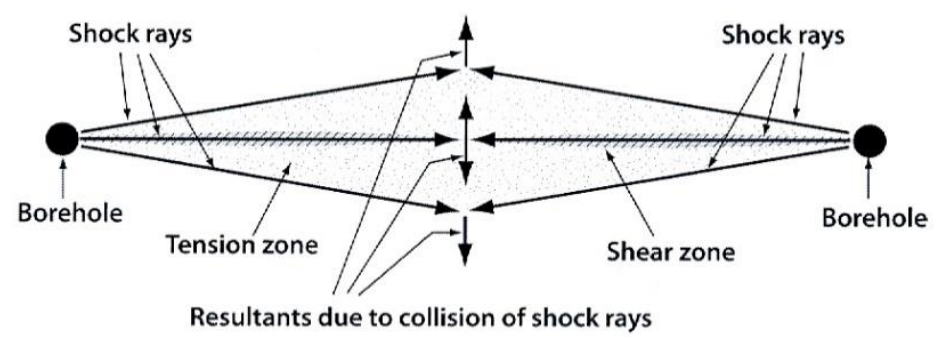

Figure 8. Schematic representation of the presplitting theory (ISEE, 2011). 


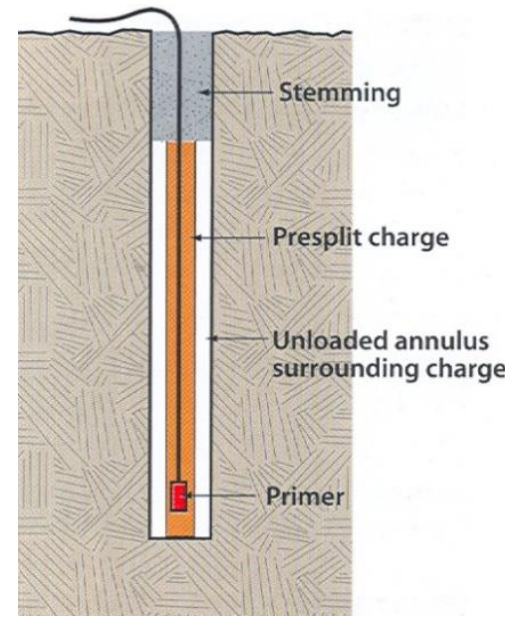

(a)

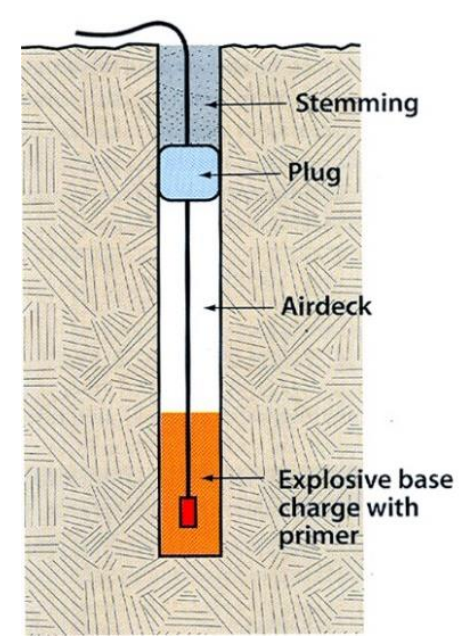

(b)

Figure 9. Left: typical presplit column load; the decoupling of the charge with respect to the hole diameter is very clearly observed (a); right, general air-decked borehole: the bottom charge is triggered by a primer, but most of the hole is unloaded and, in contact with the stemming, at the hole mouth, a plug is inserted which has the purpose of "trapping" the air cushion and ensuring a lower impact of the detonation (b). In both cases, the primer is at the bottom of the hole [11].

Figure 10 shows a scheme for applying presplitting to a production blast near the final pit slope. In this scheme it was assumed to use vertical drilled holes for the production blast, while the presplitting holes are made with an inclination of about $55^{\circ}$, considered suitable to ensure the stability of the residual bench. To make a good connection between the last row of production holes and the presplitting row, also avoiding the formation of a rock prism of too big volume, which would involve the need to perform a secondary breakage, an additional row of holes with an inclination of about $70^{\circ}$ has been performed. They have a length of $3.6 \mathrm{~m}$, to avoid convergence between the holes, with consequent excessive concentration of charge at the bottom.
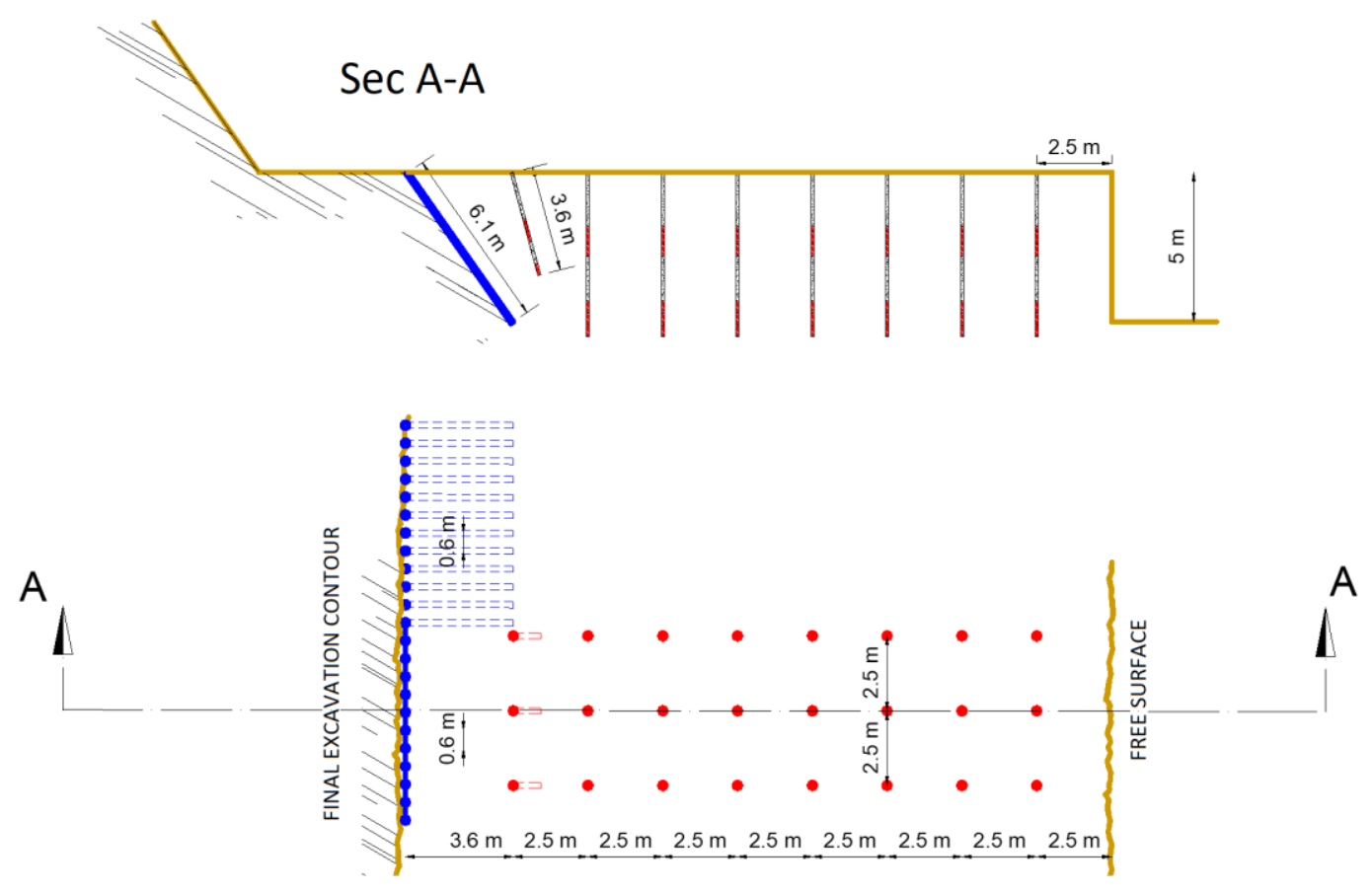

Figure 10. Example (vertical section and plan view), of the application of the presplitting to a production blast close to the final pit slope. 
Presplitting is more accurate than smooth blasting, but has the limit of not being conveniently applicable underground (especially in tunnelling), where the presence of only one free surface could compromise the result, giving rise to the propagation of unwanted fractures in the rock mass [12-15].

By combining the action of explosive with a partial mechanical notch, an improvement in the result can be obtained, although a very significant increase in time being required; this path has been tried, with some success, for decades (Figure 11). Similar improvements, again at the cost of a reduction in areal productivity, are achieved by reducing the spacing between the holes [16], up to the purely mechanical notch obtained through line drilling (Figure 4). It is still worth mentioning the case of the so-called "splitting" (Figure 12), which is applied to the detachment of regular blocks: the fracture has the purpose of isolating intact blocks that will be removed and then squared for commercial purposes. The appearance of any other fracture besides the desired one must be ruled out. The blast, conceptually similar to the presplitting, consists of an alignment of parallel holes, with small and regular spacing (usually 6 to 10 times the diameter), weakly loaded (with strongly decoupled charges - such as detonating cord - or with explosive with very low disrupting power and low detonation pressure), lying strictly in the desired detachment plane, which are detonated simultaneously. Blasts of this type require at least three free walls to allow for a small displacement of the block and are commonly applied to the exploitation of hard, silicatic, rocks (granites, gneiss and so on).

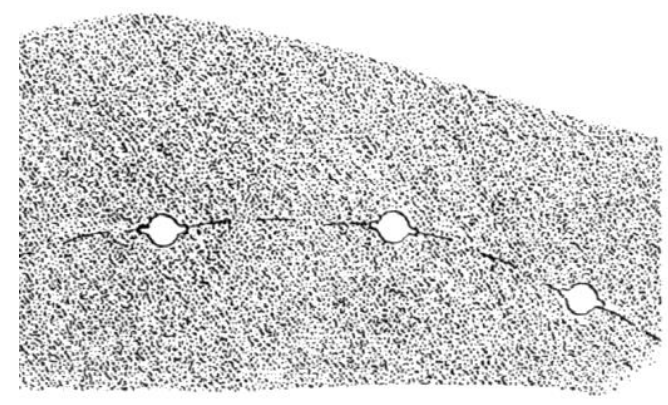

(a)

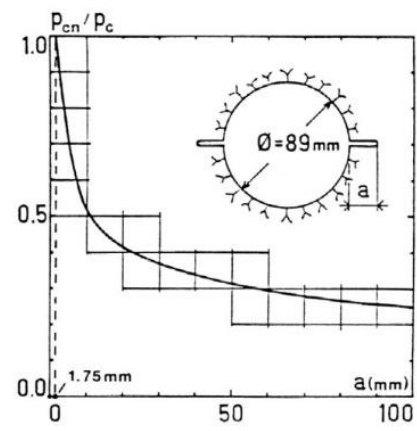

(b)

Figure 11. Left: reduced spacing thanks to holes (notched by water jet) able to guide the fracture according to the wanted direction (a). Right: gas pressure necessary for the propagation of the fracture in a blast hole with a diameter of $89 \mathrm{~mm}$, performed in granite, depending on the length of the notch. $p_{c}=$ critical pressure without notch; $p_{\mathrm{cn}}=$ critical pressure with notch [17] (b).

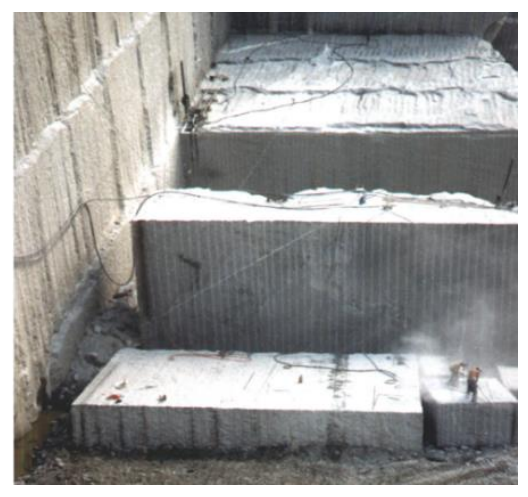

(a)

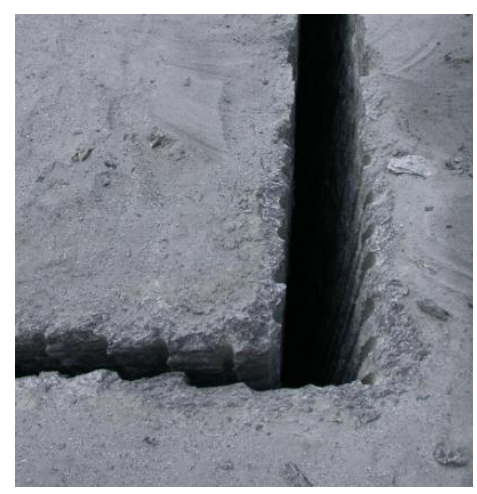

(b)

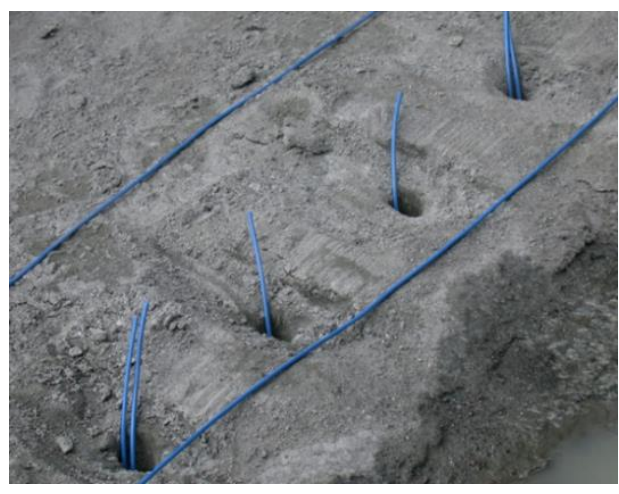

(c)

Figure 12. From left to right: application of the splitting to a granite bench (the progressive subdivision into slices and the overturning on the yard to proceed with the squaring operations is noticeable) (a); result, consisting of two vertical, perpendicular surfaces (the cut is very regular) (b); detail of the holes charged with detonating cord (which assures a decoupling of about 10 between the holes and the charge, very high compared to presplitting) (c). 


\subsection{Smooth blasting}

The most important applications of smooth blasting are in the field of tunnelling and trenches, where the ideal blast results in a minimum damage to the rock that remains and a minimum overbreak. For a lined tunnel, less overbreak means less concrete to fill the excess voids [18].

Because controlled blasting generally requires more blast holes, it takes longer to execute compared to a production blast. It requires careful design and selection of all aspects of the round-geometry, hole diameter, hole charges, hole spacing and burden, and delays as well as careful execution of the work [19]. One of the keys to successful controlled blasting is precise drilling of blast holes. Deviations of blast holes from their design quickly leads to altered spacing and burden [20], causing blast damage and irregular surfaces. Modern hydraulic drills allow a good precision, but the highest precision is obtained thanks to computer-controlled drill jumbos in homogeneous rock.

An experimental research was carried out during the excavation of a tunnel in an altered gneiss, in Northern Brazil [4]; the excavation was performed close to the surface (average overburden of about 30-40 m); RMR was estimated through 32 measurements and a mean value of 47 was found (class III, according to [21]), with only two exceptions in Class IV. Both parallel holes and V-cuts were used for the tunnel excavation; the schemes of the blasts are given in Figures 13 and 14.

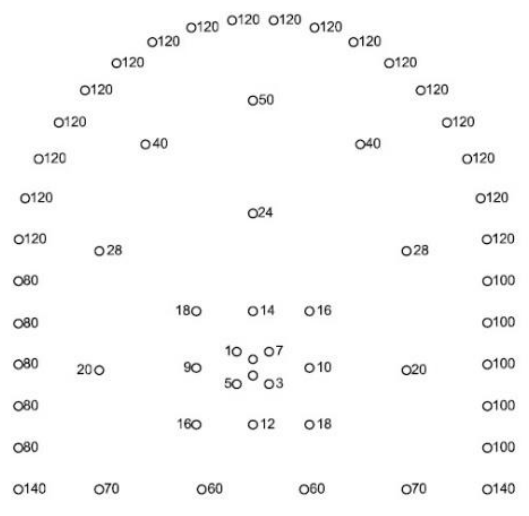

(a)

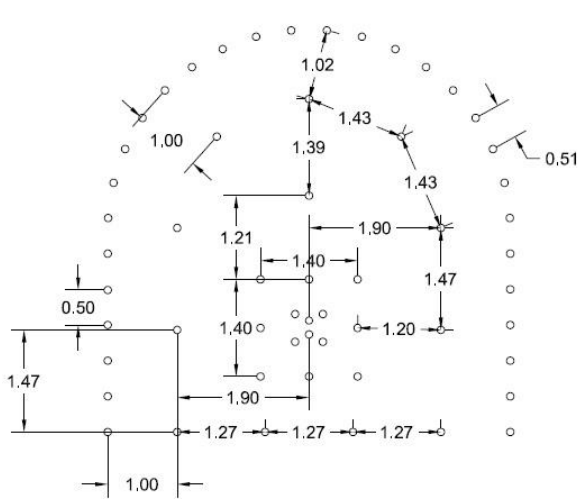

(b)

Figure 13. Scheme of parallel holes cut; Pull: 2.5 m; Surface: 30 m²; Total charge: 119 kg; Detonating cord 40 g/m: 90 m; Powder factor: $1.32 \mathrm{~kg} / \mathrm{m}^{3}$; Holes diameter: $45 \mathrm{~mm}$. Delay time: $25 \mathrm{~ms}$. On the left, numbers refer to the delay sequence (a); on the right, quotes are expressed in meters [4] (b).

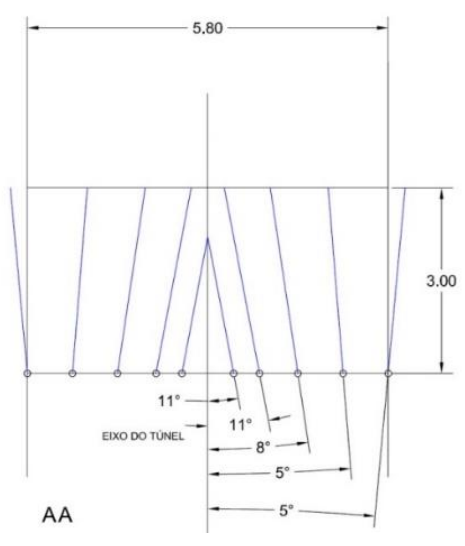

(a)

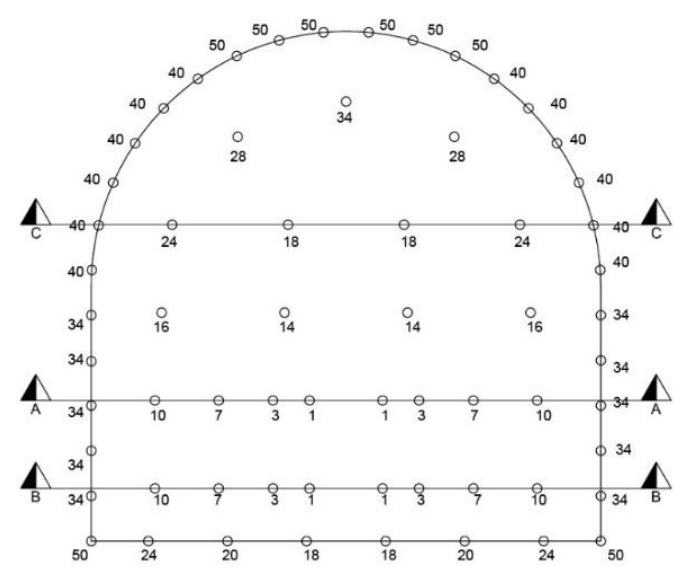

(b)

Figure 14. Scheme of a V-cut (a). Pull: 3.0 m; Surface: 30 m²; Total charge: 119 kg; Detonating cord 40 g/m: 90 m; Powder factor: $1.32 \mathrm{~kg} / \mathrm{m}^{3}$; Holes diameter: $45 \mathrm{~mm}$. Delay time: $25 \mathrm{~ms}$. On the right, the numbers refer to the delay sequence [4] (b). 
For the smooth blasting, a spacing of $0.51 \mathrm{~m}$ between the holes $(\varnothing 45 \mathrm{~mm})$, was selected, that means about 10 diameters. The contour holes were weakly loaded, as shown in Figure 15. Figure 16 shows the poor quality of the profile obtained (HCF lower than $30 \%$ ), although contour blast-holes were charged with $40 \mathrm{~g} / \mathrm{m}$ detonating cord and buffer blast-holes were employed to improve the result. The blasts were very carefully carried out, respecting the drilling design, loading and timing; buffer holes were performed to increase the chance of success of the smooth blasting, but in almost all cases HCF was not satisfactory. In this case, the explosive appears not to be the most suitable choice, due to the persistency of rock discontinuities which affect the success of the blasts. It must be noted that employing explosives in RMR class IV can be less productive and more damaging than other techniques [22]. According to [23], the damage can be correlated with the detectable peak particle velocity in the rock. The potential instability caused by the blast should be taken into consideration during rock characterization for the calculation of the supports. The importance of minimizing the fracturing around the tunnel by correctly choosing the excavation technique as a function of RMR is also emphasized by [24]. Research into the quality of blasting, then, should not only involve the technological problems, but also the rock mass characteristics, as they are strictly connected.

Parallel hole cut; charge/hole $0.21 \mathrm{~kg}$; n contour holes: 28

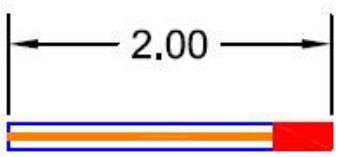

$\mathrm{V}$ - Cut; charge/hole $0.21 \mathrm{~kg}$; n contour holes: 28

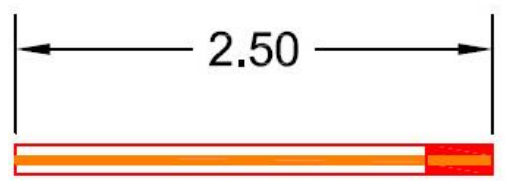

Parallel hole cut; charge/hole $0.21 \mathrm{~kg}$; n contour holes: 28

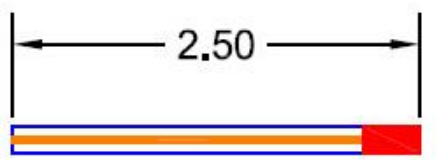

$\mathrm{V}$ - Cut; charge/hole $0.43 \mathrm{~kg}$; n contour holes: 28

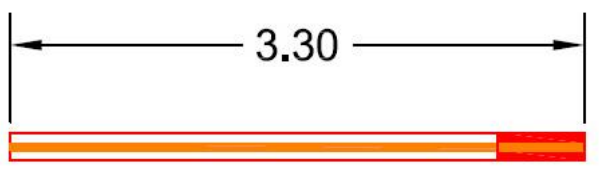

Figure 15. Details of the charges employed in contour holes. Tunnel face is on the left of the picture [4].

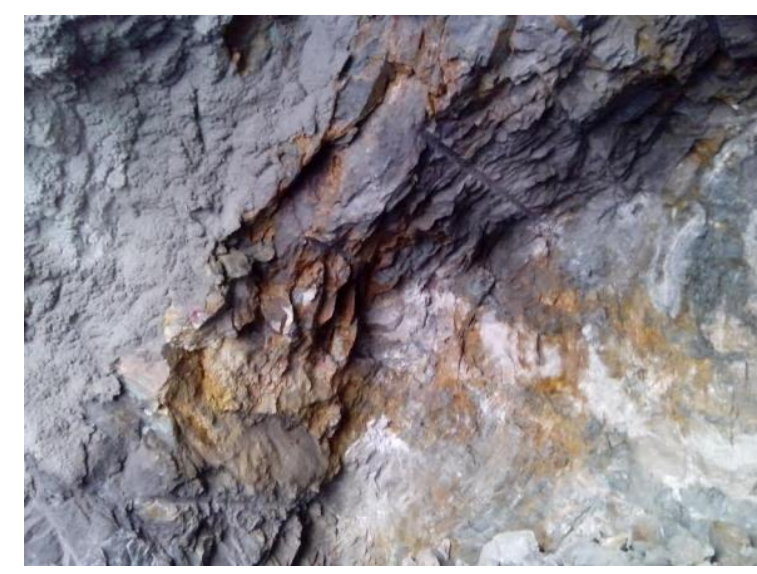

Figure 16. The poor quality of the contour obtained is noticeable [4].

\subsection{Mechanical cutting}

These are techniques that do not involve the use of explosives and therefore have a higher cost in terms of specific excavation energy. Considering the line drilling, which in few circumstances is economically reliable in ordinary excavations, is probably the most dated; drilling systems have also been created expressly intended for performing carvings 
(in soft rocks, since the first half of the twentieth century and, more recently, also in hard rocks).

An intrinsic weakness of the cutting system by line drilling is that it implies the pulverization of a volume of rock much greater than what is needful, another is given by the difficulty of precisely guiding a tool carried by a rod necessarily slender.

Cutting methods with drag tools on flexible tool holders (diamond wire and chain saw cutters) are, in principle, even more promising (Figures 17 and 18).

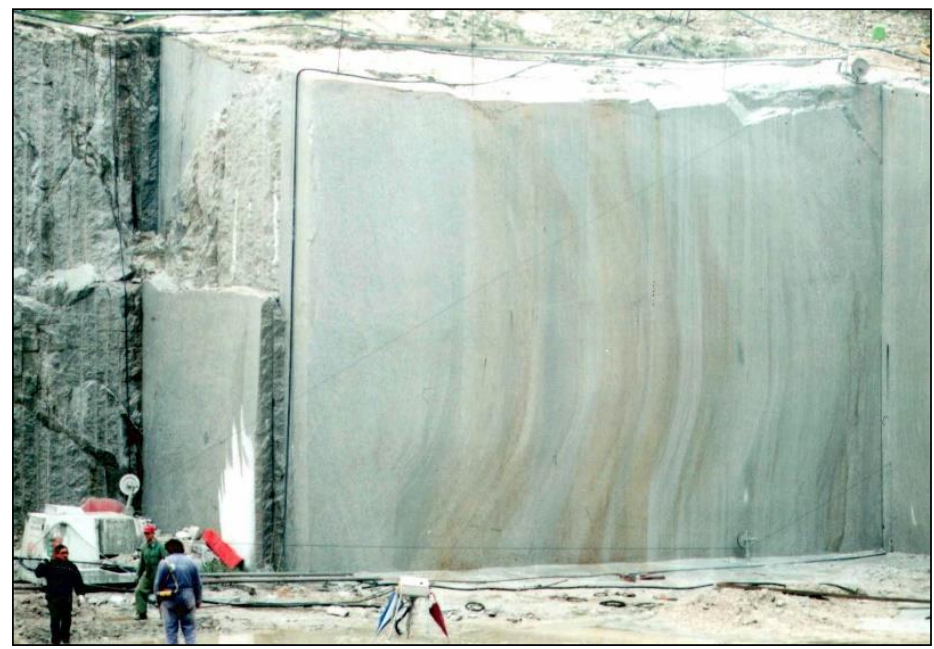

(a)

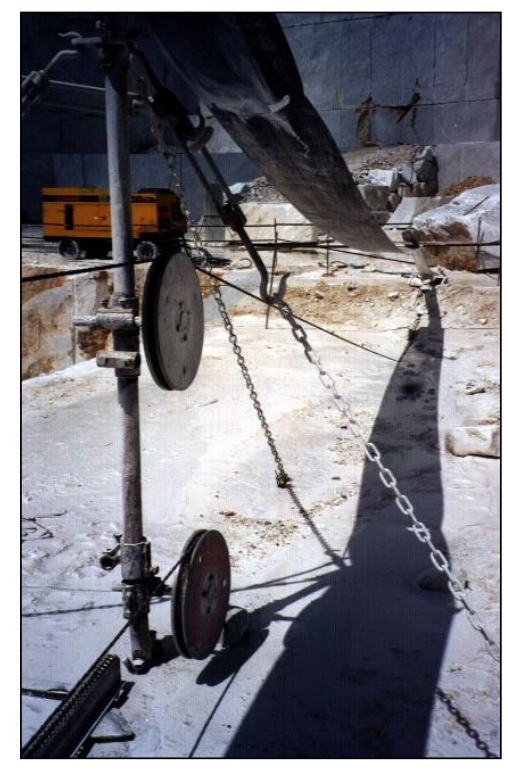

(b)

Figure 17. Left: quarry face cut with diamond wire in a Sardinian granite quarry (a). Right: detail of the cut by diamond wire saw in Carrara marble (b).

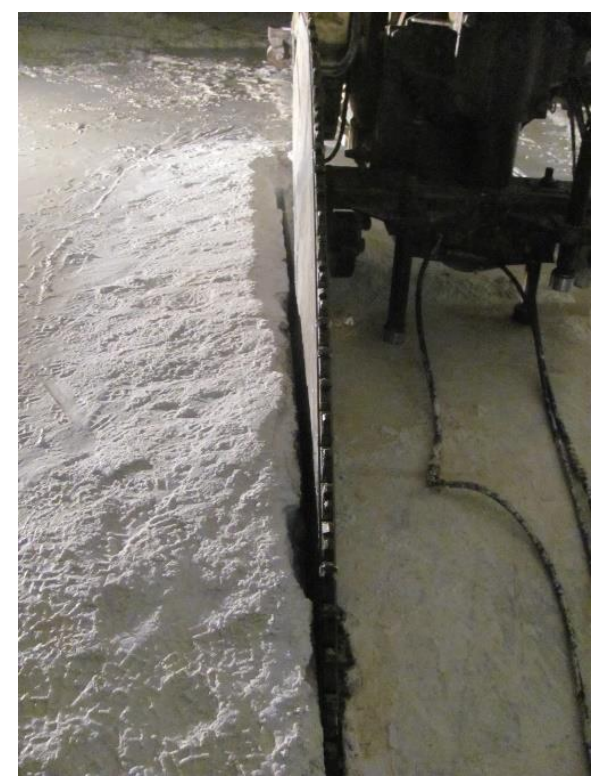

(a)

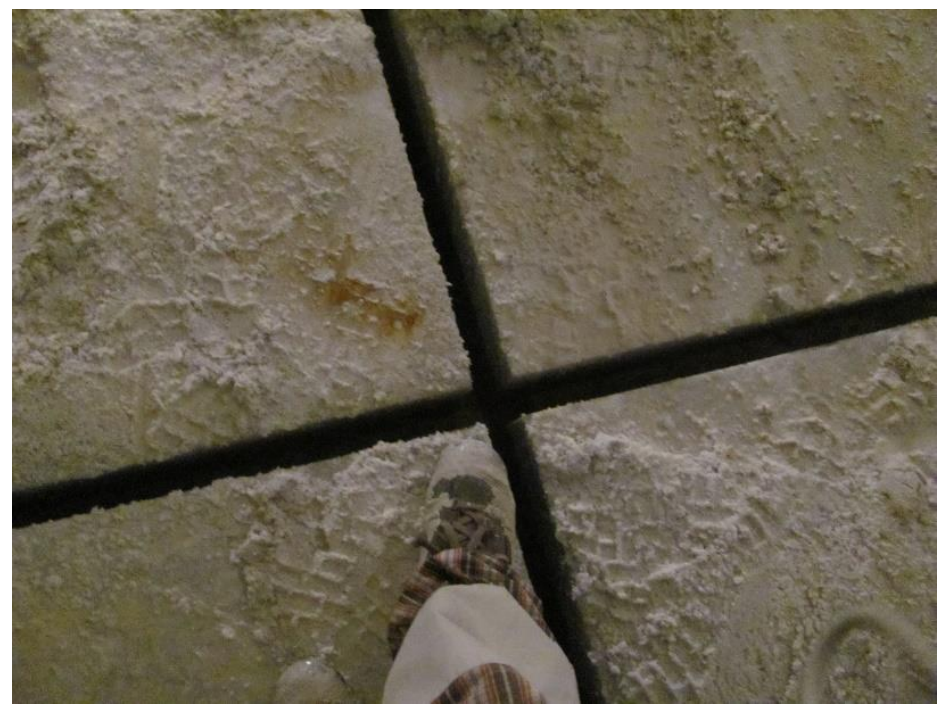

(b)

Figure 18. Left: a chain saw is performing a vertical cut in the Carrara marble (a). Right: very precise result of the isolation of blocks made by vertical cuts, perpendicular to each other, with the same technique (b). The thickness of the cut is of about $40 \mathrm{~mm}$.

The development of these techniques for hard rocks took place essentially in the sector of extraction and first squaring of dimension stones, but it is interesting to carefully 
follow the extension, albeit still sporadic, to other sectors, while remembering that, as for line drilling and for presplitting, the chances of success are very low in fractured rocks.

It should also be considered that, apart from a few prototypes of chain cutters expressly designed to pre-cut the contour of tunnels in soft rocks and with the aim of also allowing pre-lining of the volume to be removed, there is, up to now, an occasional use of machines especially made for the extraction of ornamental stones, and adapted to a different purpose.

\section{Comparison of the techniques examined}

A fair economic comparison among the techniques described above is not yet possible; however, it is useful to consider some parameters that certainly have an influence on cost and applicability.

Leaving aside smooth blasting which, despite being widely used, works in conceptually different terms compared to other techniques, the following parameters have been chosen for the analysis:

a. volume of rock removed per unit of surface $\left(\mathrm{m}^{3} / \mathrm{m}^{2}\right)$;

b. average hourly productivity of cutting surface per $\mathrm{kW}$ engaged $\left(\mathrm{m}^{2} / \mathrm{kWh}\right)$;

c. usual range of variation of the machine power $(\mathrm{kW})$;

$\mathrm{d}$. limits of the height (or depth) $\mathrm{h}$ and length 1 of the cut to be made (m).

Table 3. Comparison between the possible cutting techniques, according to some selected parameters.

\begin{tabular}{ccccccccc}
\hline Parameter & \multicolumn{10}{c}{ Technique } \\
\hline & \multicolumn{2}{c}{ Presplitting } & \multicolumn{2}{c}{ Line drilling } & \multicolumn{2}{c}{ Chain saw } & \multicolumn{2}{c}{ Diamond wire saw } \\
& Limestone & Granite & Limestone & Granite & Limestone & Granite & Limestone & Granite \\
a, $\mathrm{m}^{3} / \mathrm{m}^{2}$ & 0,005 & 0,005 & 0,05 & 0,05 & 0,05 & 0,05 & 0,005 & 0,005 \\
$\mathbf{b}, \mathrm{m}^{2} / \mathrm{kWh}$ & 0,3 & 0,15 & 0,03 & 0,015 & 0,2 & 0,1 & 0,2 & 0,05 \\
$\mathbf{c}, \mathrm{kW}$ & 100 & 100 & 100 & 100 & 50 & 50 & 50 & 50 \\
$\mathbf{d}, \mathrm{m}$ & $8 \infty$ & $8 \infty$ & $8 \infty$ & $8 \infty$ & $5 \infty$ & $5 \infty$ & 1020 & 1020 \\
$\mathbf{b ~ c}, \mathrm{m}^{2} / \mathrm{h}$ & 30 & 15 & 3 & 1,5 & 10 & 5 & 10 & 2,5 \\
\hline
\end{tabular}

Some clarifications are needed:

1. in the case of presplitting, it is assumed that the most commonly adopted diameter $\varnothing$ is used for long holes made with a heavy drilling machine $(50 \mathrm{~mm})$ and a spacing of around 10 diameters; obviously, the use of smaller diameters, or larger spacing or, possibly, longitudinal notches on the wall of the holes can lead to a reduction in the volume to be sacrificed, although not necessarily giving rise to an improvement in the result;

2. reference is made to the net production, referring only to the working hours of the machine, not considering the times due to installation, repositioning, tool change, hole loading in the case of presplitting, etc., and to the installed power: this is not, therefore, an energy cost, but a rough indicator of the latter;

3. the usual value of the installed power of a single machine is reported; obviously, in the case of presplitting, several machines can easily be used in a single operation, while this rarely happens with the other techniques;

4. the symbol $\infty$ indicates, for the length, the case in which there is no limit; of course, even in these cases, there is the need to reposition the machine as the cutting proceeds;

5. the product $b \cdot c$ is the net productivity of a single average machine (installed power).

The values shown are approximate, but they indicate how difficult it is still to displace presplitting from its position as a technique of minimum cost and maximum productivity. 
However, the other techniques can be taken into consideration when it is intended to obtain:

- a more satisfactory solution to the problem of isolation from vibratory effects (which will never be complete, since the elastic waves can diffract around the notch) which, in the case of presplitting, is due to the fact that the notch itself generates a seismic disturbance not negligible;

- a remarkable regularity of the wall;

- the exclusion of the propagation of new fractures to the rock which must remain in place.

Such cases have in common the need to carry out particularly sophisticated works.

\section{Examples of application and perspectives of mechanical cutting techniques}

A simplistic way would suggest that the field where these expensive isolation techniques could more easily spread is that of rock excavation works involving large volumes, as the surface/volume ratio (and therefore the incidence of the largest operation unit cost), decreases as the volume increases.

On the other hand, it is found that the still sporadic examples reported in the literature concern works involving the removal of small volumes, and this probably happens in cases where both the unit cost and the unit fee are higher. Furthermore, these are generally surgical operations on large artifacts rather than natural bodies.

In ornamental stone quarries, it is quite usual to make cuts, mostly with a diamond wire saw, intended solely to isolate a volume, which must subsequently be removed from the deposit that will be "gently" treated to obtain healthy blocks. An economic comparison with civil works regarding the additional cost of mechanical cuts compared to an ordinary presplitting, which would solve the same problem even if less perfectly, may not be fair, as the quarry manager already has machinery and workers available. Moreover, in ornamental stones quarries, the work schedule is not pressed by the need to minimize the duration of the operation, the execution of which is the preparation of a future activity that can be superimposed on ordinary production. However, a comparison of the times can be established by applying to a hypothetical case the values obtained from the result of the operations actually performed.

A conceptually similar operation is quite common in the underground exploitation of ornamental stones and, above all, of slates. A room must be created above the bench to be exploited, in the non-exploitable rock of the roof, in which the machines designed to cut and extract the commercial blocks from the underlying layer will operate. These chambers are excavated with explosives, but by making a preliminary insulation cut: this cut can be performed by presplitting, but this practice tends to be abandoned, as it does not guarantee enough from the propagation of fractures to the useful bench. The machines currently used are chain cutters, which are also used in rocks harder than ordinary marbles (not yet, however, in granite) thanks to the diamond sintered tools. The gross time required to cut $1 \mathrm{~m}^{2}$ is approximately 8 minutes, with an average productivity of approximately $7.5 \mathrm{~m}^{2} / \mathrm{h}$.

Certainly, presplitting is faster and less expensive than mechanical cutting, but this alternative should be taken into consideration for cases where the perfection of the cut and the regularity of the surface are essential, also because, if in the field of D\&B probably an optimum has already been achieved, significant progress is still wait in mechanical cutting:

- the yield of diamond wires, up to the ' 990 s rarely used in granite, as it did not exceed $5 \mathrm{~m}^{2} / \mathrm{m}$, has risen to about $13 \mathrm{~m}^{2} / \mathrm{m}$;

- the applicability of chain cutters, practically limited to limestone rocks, is extended to serpentines and sandstones thanks to new materials for tools, and the machines also reach net productivity in these rocks similar to those of marble;

- longer tool life, in any case, is reflected in higher gross productivity. 
However, it is important to take into account the specific excavation energy deriving from drilling (presplitting or line drilling) and from cutting operations. Since this parameter is related to the grain size distribution of the materials after the excavation, a finer fragmentation means a higher energy cost: drilling requires, by comparison with mechanical excavation, the greatest amount of specific energy (Figure 19), but the cut made with micro-tools such as diamond wire or chain saw forces the tools to break up portions of rock with a very small depth of cut (generally, a few tenths of a mm) and therefore involves a very high energy cost.

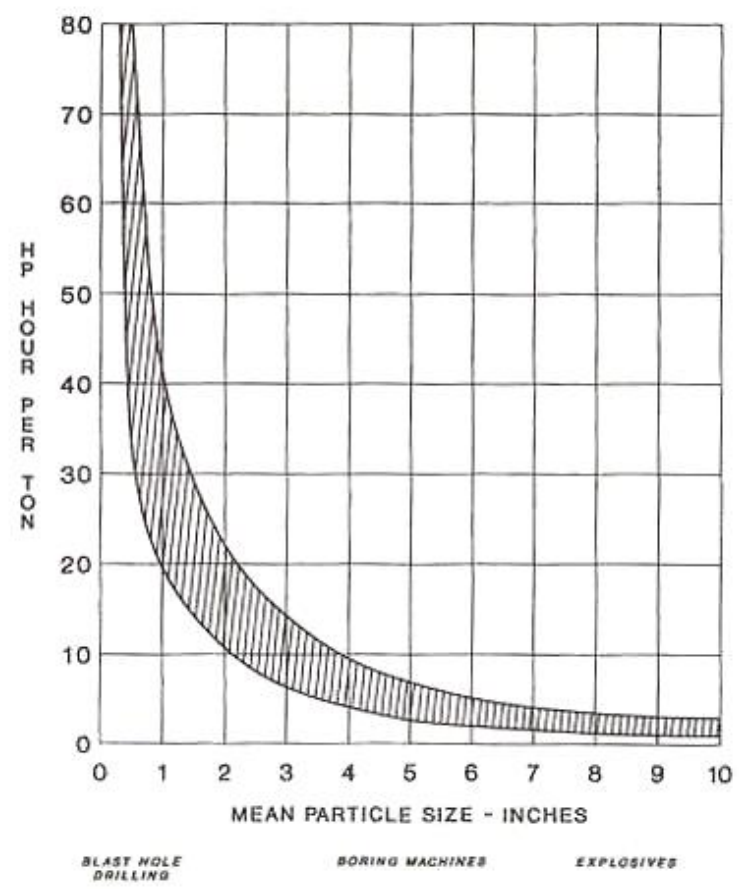

Figure 19. Correlation between the energetic cost of excavation of the rock, expressed in CVh/t and the average size of the fragments obtained, expressed in inches. The "ranges" designate: "Blast Hole Drilling": drilling of blast holes; "Boring Machines": machines for the mechanical excavation of tunnels or shafts; “Explosives": blasting [25].

\section{Conclusions}

The reasons why the development and success of mixed excavation techniques is expected, where the explosive does the brutal work for which it was born at low cost, and a mechanical cutting system sets the boundaries to its action, however, do not consist only in the greater perspective of improvement of those systems, but also in the fact that they are spreading rapidly out of the narrow niche in which they initially developed, that is the production of dimension stones.

Fields in which these techniques are spreading with great differentiation are that of demolitions, the correction of large artifacts (especially hydraulic engineering works), harbours, roads. Large cuts are always more frequent, opportunistic methods disappear, and special and versatile assemblies for diamond cutting machines of various types are developed, actually universal in terms of the materials on which they act, and the cost of synthetic diamond is lowered. Indeed, not only the coast is lowered but new ways of using diamond are developed, as for example in widia-diamond composite tools, which still have difficulty in granite, but already allow to saw with relative ease rocks of medium hardness.

Contour pre-cut excavation, which has been common in exploitation of salts, coal and other soft rocks for many years, is now possible in a variety of rocks, and there are no constraints on paths other than linear ones, as already work, at least as prototypes, cutting machines suitable for following curvilinear contours. 
It is difficult to think that these trends do not end up also affecting ordinary rock excavations, especially since a growing share of them affects urban areas and that the granite of Northern Europe, where presplitting has been most successful, is not the only reality on our planet.

Funding: This research received no external funding.

Conflicts of Interest: The authors declare no conflict of interest. 


\section{References}

1. Hermanson, J. Rock Drilling on a vertical Wall: Problem solving at Crazy Horse. J Explos Eng 1996, 13(7), 12-14.

2. Muehl P. Nose blasts present explosives engineering challenges. J Explos Eng 1993, 11(4), $43-45$.

3. Seccatore, J.; Romero Huerta, J.; Sadao, G.; Cardu, M.; Galvão, F.; Finoti, L.; Rezende, A.; Bettencourt, J.; De Tomi, G. The influence of charge distribution on the grindability of the blasted material, Proceedings of the 11th International Symposium on Rock Fragmentation by Blasting, The Australasian Institute of Mining and Metallurgy (Australia), FRAGBLAST11, Sydney 2426 August, pp. 6, 2015, ISBN: 9781925100327

4. Seccatore, J., Golin, F., Cardu, M., Munaretti, E., Bettencourt, J., Koppe, J.C. (2015b). Evaluating the Effects of Non-coaxial Charges for Contour Blasting, Proc. 11th International Symposium on Rock Fragmentation by Blasting, The Australasian Institute of Mining \& Metallurgy (Australia), FRAGBLAST 11, Sydney 24-26 August, pp. 12, 2015, ISBN: 9781925100327

5. Du Pont, Blasters' Handbook (1977), 175th Edition, E.I. du Pont de Nemours \& Co., Arthur LaMotte Ed., 494 pp.

6. Sandvik - Tamrock Corp. Rock Excavation Handbook for Civil Engineering. Matti Heiniö Ed. 1999, 364 pp.

7. Haoran, H.; Wenbo, L.; Peng, Y.; Ming, C.; Qidong, G. A vibration-isolating blast technique with shock-reflection device for dam foundation excavation in complicated geological conditions. Shock Vib, 2018, Article ID 8029513, 11 pp.

8. Primavori P. Pianeta Pietra. Giorgio Zusi Ed., Verona, 1999; 326 pp.

9. Hoek, E.; Brown, B.T. Practical Estimates of Rock Mass Strength. Int J Rock Mech Min Sci 1997, 34(8), $1165-1186$.

10. Chu, H.; Yang, X.; Li, S.; Liang, W. Experimental investigation of the propagation and attenuation rule of blasting vibration wave parameters based on the damage accumulation effect. Shock Vib, 2018, Article ID 2493149, 9 pp.

11. International Society of Explosives Engineers Ed. ISEE Blasters' Handbook, XVIII ed.; Cleveland, USA, $2011 ; 1030$ pp.

12. Cunningham, C.V.B.; Goetzsche, A.F. The Specification of Blast Damage Limitations in Tunnelling Contracts. Tunnelling and Underground Space Techn 1990, 5(3), 193-198.

13. Zhou, Z.; Cheng, R.; Cai, X.; Jia, J.; Wang, W. Comparison of Presplit and Smooth Blasting Methods for Excavation of Rock Wells. Shock Vib, 2019, 2019, Article ID 3743028, 12 pp. https://doi.org/10.1155/2019/3743028.

14. Singh, P. K.; Roy, M. P.; Paswan, R. K. Controlled blasting for long term stability of pit-walls, Int J Rock Mech Min Sci 2014, 70, 388-399.

15. Wang, F.; Tu, S.; Yuan, Y.; Feng, Y.; Chen, F.; Tu, H. Deephole pre-split blasting mechanism and its application for controlled roof caving in shallow depth seams, Int J Rock Mech Min Sci 2013, 64, 112-121.

16. Hagimori, K.; Terada, M.; Ouchterlony, F.; Furukawa K.; Nakagawa, K. Using slot drilling to reduce vibrations and damage from tunnel blasting in urban areas. Proceedings of the 4th International Symposium on Rock Fragmentation by Blasting, Wien, 1993, pp. 97-104.

17. Niklasson B.; Keisu M. New techniques for tunnelling and drifting. Proceedings of the 4th International Symposium on Rock Fragmentation by Blasting, Wien,1993, pp. 167-174.

18. Satici Ö. Drilling and Blasting as a tunnel excavation method. Middle East Technical University-Department of Geological Engineering 2006, Ankara, 24 pp. DOI: 10.13140/RG.2.1.2991.2400.

19. Qiu, X.; Shi, X.; Gou, Y.; Zhou, J.; Chen, H.; Huo, X. Short-delay blasting with single free surface: results of experimental tests. Tunnelling and Underground Space Techn 2018, 74, 119-130.

20. Langefors U.; Kihlström B. 1967. The modern technique of rock blasting, 2nd ed.; Almqvist \& Wiksell, Stockolm, 405 pp.

21. Bieniawski, Z.T. Engineering classification of jointed rock masses. Trans South Afr Civ Eng 1973, 15(12), 335-344.

22. Innaurato, N.; Mancini, R.; Cardu, M. On the Influence of the Rock Mass Quality on the Quality of the Blasting Work in Tunnel Driving. Tunnelling and Underground Space Techn 1998, 13, 81-89.

23. Page, C.H. Controlled blasting for underground mining. Proceedings of the 13th Conference on Explosives and Blasting Techniques, ISEE, Miami, USA, 1987, pp. 33-48.

24. Holmberg, R.; Larsson, B.; Sjoberg, C. Improved stability through optimized rock blasting. Proceedings of the 10th Conference on Explosives and Blasting Techniques, ISEE, Orlando, USA, 1984, pp. 166-171.

25. Mancini R.; Cardu M. Scavi in roccia - Gli esplosivi. Publisher: Hevelius Ed., Benevento, 2001, 295 pp. 